the emulsion be sterilised at $60^{\circ}$ or $100^{\circ} \mathrm{C}$. On this staphylococcus agar the bacillus grew more luxuriantly than on the blood media. The colonies were larger and less transparent. The organism also grew well on a streptococcus agar similarly prepared. The growth here was not so vigorous as on staphylococcus agar, but more so than on blood agar. The organism died out very quickly in cultures; it could not be subcultured on blood agar when older than two or three days. In blood bouillon it retained its vitality somewhat longer. In the original pus from the knee-joint (which contained a considerable proportion of blood) the germ remained alive in pure culture for 31 days.

Pathogencity.-Intravenous and intraperitoneal inocula. tions into the rabbit and intraperitoneal inoculation into the guinea-pig gave negative results. Inoculations into white mice of a culture from blood agar or blood bouillon similarly failed, but inoculation of an emulsion of the growth on a staphylococcus agar slope produced a septicæmia fatal in 24 hours. Pare cultures of the bacillus were obtained from the heart's blood, the liver, and the spleen. This power of producing septicæmia in a mouse and the fact that in the patient the bacillus must have travelled by the blood to reach the affected joint, are the only points in which this organism does not conform to the typioal bacillus of Pfeiffer.

One had now to ask oneself with Cohen: "Est-ce du bacille de Pfeiffer qu'il s'agit dans ce cas? Ou bien seulement d'un bacille identique d'aspect? Y aurait il autant de variétés de coccobacilles hémophiles qu'il y a de variétés de streptococques ou de bacilles acide-résistantes?" Cohen adds pathetically: "La solution de ce problème nous semble bien ardue."

Investigation of the literature shows no case similar to the above where a single joint was attacked by a bacillus resembling the bacillus Pfeiffer. Dudgeon and Adams report a case of a baby, 10 months old, with necrosis of the radius and suppuration of the elbow-joint followed by meningitis and abscess of the hip-joint. Post mortem the bacillus Pfeiffer was found in pure culture in the affected bones and joints and over the brain surface. Cohen has also found an influenza-like bacillus in the purulent fluid of joints in a case which died from cerebro-spinal meningitis. In both these cases there was a true septicæmia. Pfeiffer, Weichselbaum, Cantani, jun., Joachmann and others maintain that the bacillus is never found in the blood in the course of influenza. Canon, Meunier, and Ghedini, on the contrary, state that they have found it in the blood in these circumstances. Thursfield quotes two cases where he isolated typical influenza bacilli from the blood; both of these patients recovered.

An important contribution towards the elucidation of this question of the unity of the bacillus Pfeiffer has been made by Cohen in his report of three cases of septicæmic cerebrospinal meningitis. In these cases the organism was morphologically and culturally almost identical with the bacillus Pfeiffer, but when injected intravenously into a rabbit it killed the animal by a true septicæmia-not by toxæmia, as is the case with bacillus Pfeiffer. Cohen believes himself authorised to consider this microbe as representing an independent species.

In the present case we do not feel at liberty to claim the germ as belonging to a separate species. Although a septicæmia was produced in the mouse it is to be noted that this was possible only with the germ when grown on staphylococcus agar and not with the cultures on blood media, which had been those used by Pfeiffer.

Now Bordet has shown in his researches on the influenzalike bacillus found in whooping-cough that the characters of the "staphylococcus germ" (organism cultivated on sterilised agar which had previously been a culture medium for staphylococcus) differed in many respects from those of the "blood germ" (organism cultivated on blood media). "With regard to the agglutination reaction, the bacterium behaves as if it belonged to two different species depending upon the nature of the medium in which it is grown." The staphylococcus germ loses the power of being agglutinated by a serum which has a marked agglutinating action on the blood germ. It is quite rossible that in our inoculation experiments with white mice we were dealing with a "race résistante" (made resistant in vitro by the nature of the staphylococcus medium), and it would be quite unjustifiable to argue from this that the original germ was not bacillus
Pfeiffer. Until we know more of the possibilities of modifying the bacillas Pfeiffer by the action of various culture media, we shall not proceed far in our attempts to classify the influenza-like bacilli found in various pathological conditions.

I am indebted to Dr. J. A. Adams, under whose charge this case was admitted, and who very kindly furnished the clinical details. I am also much obliged to Mr. David McCrorie for performing the animal experiments necessary. Glasgow.

\section{A CASE OF ACUTE PHTHISIS FOLLOWING TYPHOID FEVER.}

BY W. SCARISBRICK, M.B., B.S., B.Sc. LOND., D.P.H., M.R.C.S. ENG., L.R.C.P. LOND.,

ASSISTANT MEDICAI OFFICER OF HEALTH OF THE CITX OF CHESTER.

ON Feb. 10th, 1911, a female patient, aged 13 years, was admitted to the Chester Isolation Hospital as a case of scarlet fever having the following history. Sore-throat and headache on Jan. 29th, but no vomiting, diarrhœa, or other symptom noticed until Feb. 9th, when the patient was thought to have scarlet fever desquamation. She was seen by me on the day of her admission to the isolation hospital, and the following notes were made: "Rash nil, tongue shows no special characteristic, throat normal. Suspicious denudation on the left heel observed, very like scarlet fever peeling, but no further signs of desquamation noted either at the time or subsequently. Heart and lungs normal; pulse and respiration 120 and 32 respectively, both showing an increase above the normal rate, ascribed, in view of the absence of signs in the chest, to excitement due to removal to hospital. Temperature $101.2^{\circ} \mathrm{F}$. Rose spots absent. No further signs noted."

On Feb. 14th the brother of the above patient was also admitted to the hospital as a case of scarlet fever, with signs and symptoms still more indefinite than those of his sister. This second case is still under observation, and I hope at a future date to record some interesting facts concerning the course of his illness.

Returning to the case of the girl, the subsequent history is interesting. On Feb. 14th it was noticed that the spleen was markedly enlarged, no rose spots were present (a sign which, in $\mathrm{my}$ experience, is rare in soung typhoid patients), and there were no signs of peeling. Some of the patient's blood was taken in order to test its agglutinative powers, but it was found to be negative to cultures of typhoid, paratyphoid A, and paratyphoid B. Nothing else worth recording was noted for the first few days of the patient's sojourn in hospital. On the 17th (a week after admission) the temperature dropped to normal for the first time since coming under our notice, and thereafter for the next week or so assumed an intermittent type, with the acme of the crest a little lower on each succeeding day, except one. In fact, the chart showed all the appearances of a case of enteric fever in the fourth week of illness, the temperature falling by lysis. During this period, and for the following fortnight, it was noted that the pulse and respirations varied very little from normal, the former only reaching 100 on one or two occasions and the latter rarely exceeding 20-24. The patient herself appeared, and in fact was, much improved, and complained of feeling hungry. A further sample of blood taken on Feb. 19th, and tested for Widal's reaction again gave a negative result. On the 25 th (a fortnight after admission) the temperature was normal and remained below $98^{\circ}$ for 24 hours. At this period a third sample of blood was taken, and on examination was now found to be positive to bacillus typhosus in dilutions 1 in 25 and 1 in 60 . In a dilution of 1 in 100 partial agglutination was also obtained. The diagnosis of typhoid fever, which might be said to have been doubtful previously, seemed now settled. On the next evening the temperature rose again and for the next week assumed a hectic type of increasing severity. The patient obviously had some kind of a relapse. She was restless and did not want her milk. The tongue was furred but moist. The respirations remained the same, 20 per minute, but the pulse gradually became more frequent, averaging 96 per minute on March 2nd. On this date the heart and lungs appeared to be normal, the spleen was palpable, and the 
patient was passing pea-soupy stools, but there was no diarrhœa.

On March 6th the patient complained of pain in the abdomen below the xiphisternum. There was no vomiting, no tenderness or rigidity on palpation, and no evidence of perforation or peritonitis. From this date onwards the patient became much weaker. The temperature reached well over $103^{\circ}$ every day, and tepid sponging had continually to be resorted to. The pulse- and respiration-rates gradually increased, and the patient began to show signs of cyanosis and to cough a little. On the 9th (four weeks after entering hospital) signs of lung mischief were observed for the first time, crepitations being heard in the right axilla. Slight dulness was observed in the right side, but the rest of the lungs appeared clear. During the next few days the patient became much worse, the symptoms increased rapidly in severity, crepitations were heard over both apices back and front, and the breathing was bronchial in character. Dulness to percussion was quite marked on both sides of the chest. The respirations reached 60 , and the pulse 160 per minute. On the 13th a further sample of blood again gave a positive result under Widal's test. On the 14th, after repeated attempts, the patient was persuaded to expectorate a little sputum. This on the usual staining examination showed numerous tubercle bacilli. On the 15th, although it was considered hopeless, some of the patient's blood was drawn and inoculated into bile, but the culture proved sterile. The patient sank rapidly and died on the 16th.

In summarising the features of the above case it might be said that the only tangible evidence was the finding of tubercle bacilli in the sputum. Unfortunately consent could not be obtained for a post.mortem examination, otherwise the question of typhoid conld easily have been cleared up by an inspection of the small intestine. Bacteriological examination of the fæces, indeed, was thought of, but a convenient opportunity did not present itself. At the same time, the Widal test giving a positive reaction twice, the remarkable lysis-like drop of the temperature during the fourth week of illness (the onset occurring about Jan. 29th), the enlarged spleen, and the slow rates of pulse and respiration previous to development of lung sigus, all point strongly to an initial attack of typhoid fever stirring up a dormant tubercular focus in the lung.

In conclusion I must express my indebtedness to Dr. J. R Currie, medical officer of health of the city of Chester, for permission to use the notes on this case.

Chester.

\section{ENDEMIC TETANY IN THE GILGIT VALLEY.}

BY ROBERT MCOARRISON, M.D. R.U.I., M.R.C.P. LOND., CAPTAIN, INBIAN MEDTCAL SERVICE; AGENCY SURGEON, GILGIT (KASHMIR)

ENDEMIC tetany has been described as occurring in such large cities as Vienna and Heidelberg, but little seems to be known of the malady in rural districts. The endemic tetany of the city possesses very definite characters; it has a marked relationship to the time of year, usually appearing in the spring; it has a tendency to assume epidemic proportions ; and it is very local in its distribution. A consideration of the malady as it is found to occur in this part of the Himalayas may afford an interesting and, it is hoped, a useful contrast. I shall confine myself to a consideration of its etiology and to a few points of treatment. Its symptomatology does not differ from the usual text-book descriptions. Etiology.

The disease is a common one in India, and is well recognised by the people, whose term, "hatti fallategen" (meaning "a turning in of the hands"), admirably describes it. I have come across 60 odd cases of the affection, and these are a very small proportion of all cases occurring in the district.

The distribution of tetany is peculiarly local, and appears to correspond more or less with the distribution of goitre. One meets with it most commonly, for example, in localities where the endemicity of goitre is highest; it does not appear to prevail in parts of this country where goitre is not found. In Hunza goitre is urknown; so is tetany. In Barmis, also, and in the Ishkomin valley, $I$ have been unable to find a case ; in these places goitre either does not occur or its endemicity is very slight.

Sufferers from tetany appear to be able to rid themselves of it by going to a locality where it does not prevail. A young married woman had suffered from the disease during two successive springs while living in Gilgit. She then went to reside at Ishkomin, where she lived three years, and during that time was free from tetany. She became pregnant and subsequently suckled her child while there, and, as we shall see, pregnancy and lactation favour the development of the malady. On her return to Gilgit she again suffered.

In India tetany is a disease of women; I have only met with one case in the male. The condition also affects women at a very definite period of their lives-namely, at the childbearing period. Girls under the age of 15 years do not appear to suffer. It is almost entirely confined to married women, but as practically every girl over the age of 15 years is married, and over the age of 18 years is a mother, too much stress cannot be laid on the influence of the married state. One cannot determine the extent to which unmarried women would suffer. The disease is most common in women between the ages of 20 and 30 years; more than half of $m y$ cases were in women of this age. My youngest patient was a girl of 15 years; my oldest a woman of 42 years. The disease also usually makes its first appearance between the ages of 15 and 30 years. Only five cases in the present series are noted to have commenced after this age.

There is a marked family tendency to tetany; when a daughter suffers her mother, and possibly her grandmother, has suffered before her. Sisters also are frequently affected. This family nature of the complaint is not due to any greater liability to contract it in a household where there are other sufferers. It is a true predisposition to the disorder.

The children of women who suffer from tetany are frequently cretinous. Of 56 women thus afflicted, 13 were the mothers of cretins. This proportion is so high that I give to tetany a prominent place amongst those conditions which, when present in the mother during pregnancy, have an influence in the production of cretinism in the child. Tetany in a pregnant woman is, in short, a signal of danger to the child, and is an evidence that treatment should at once be undertaken.

Menstruation appears to increase the frequency and the severity of the attacks of tetany, especially so when this function is in any way disordered.

The association of this disease with pregnancy ard lactation is one of its most striking characteristics. Tetany commonly develops during pregnancy, more commonly, 1 think, during the second than the first. Sometimes the onset is during lactation. Attacks are undoubtedly worse should the patient be pregnant or suckling a child. Tetany also arises most frequently, and the attacks are most severe during the later months of pregnancy or the earlier months of lactation. Some women appear to suffer more during pregnancy than during lactation; in other cases the reverse is true. It appears to be the rule that attacks of the disease cease when child-bearing ceases. The almost complete limitation of tetany to women is a most striking proof of the importance of pregnancy and lactation in favouring its development.

The seasonal prevalence of tetany-its limitation to the spring months, except in rare instances-is its most distinctive feature. It begins to manifest itself about the middle of February and prevails until "the ripening of the mulberries," about the end of May. After this month the temperature rises very rapidly and the disease ceases abruptly. Cases are unknown to develop during the summer months. A few of the cases in the present series developed during the autumn or winter months in association with pregnancy or lactation. The attacks were in these cases of a mild type and the intervals between them of longer duration than is the rule during the spring. Such cases I believe to be examples of the "tetany of pregnancy," and to have arisen more or less independently of endemic influences. During the spring the disease is so common that it may be said to be epidemic. A woman who has suffered from the malady during one spring is practically certain to suffer during succeeding springs. In several of my cases recurrences have manifested themselves every spring for years, in one case for $18 \mathrm{y} \epsilon$ ars. I have $m \in t$ with only a single instance in which 